functions, should ensure the place of this book in all medical libraries, casualty departments and general practitioner bookshelves.

PaUl TURner,

St Bartholomew's Hospital, London ECIA 7BE.

\section{Psychiatry Revision. Aids for Postgraduate Trainees}

By Dorcas Bird, Jonathan Bird and Glynn Harrison. Pp. 352. Churchill Livingstone, Edinburgh, 1982. $\mathbf{6} 6.00$.

This is an interesting new book written by 3 young psychiatrists of Senior Registrar status who have recently obtained their M.R.C.Psych. It is divided into two sections of equal length on multiple choice questions and on essay questions and a shorter, middle section giving details of specimen case histories with specimen answers to questions about them. The book is clearly going to be very useful and it is likely to help many preparing for the M.R.C.Psych. examination at which it is specifically aimed.

The first section on multiple choice questions is very wide in its scope and very searching. It covers child psychiatry and psychotherapy and subnormality as well as the usual range of adult work. It seems to the reviewer, who is unfortunately some 20 years on from doing the examinations himself, that the level of detailed knowledge needed is considerably greater than is perhaps clinically necessary, and much of the information requested is of the sort that one might look up in a book if it were wanted.

The case histories are really very straightforward after the multiple choice questions and are about patients that one might quite readily meet and the diagnosis is usually not difficult. The differential diagnoses are however well discussed. It is a pity that there are no cases of neurotic illness and little attempt to pick up pointers in psychotherapy that might have come up in the more complicated case histories that might then have been obtained.

The last section of chosen essay questions could do very well in its own right for a mini textbook. Most of the difficult and contentious areas of present day psychiatry are fully discussed. Many of the essays are model answers and the few references for extra reading will obviously be extremely helpful.

In sum, this is a very useful book which is likely to fill a gap and to go on to further editions.

M. J. TARSH,

Hope Hospital,

Salford M6 8HD.

\section{Sexual Abuse. Incest Victims and Their Families}

By JEAN Goodwin with contributors. Pp. 209. John Wright, PSG Inc., Boston, Bristol, London, 1982. £13.50.

It is 20 years since Kempe made physicians aware of the fact that Caffey's syndrome was caused by parents battering their children and not by some rare genetic defect. Physicians have always been aware of the intrafamilial sexual abuse of children, but have comforted themselves with the thought that it was a rare phenomenon. They can comfort themselves no longer. This book, well organised and well written as it is, makes sickening reading, but those of us who have the professional care of children will have to read it. Jean Goodwin, psychiatric consultant to a child care protection agency in New Mexico, relentlessly builds up an irrefutable case for doctors becoming more alert to the problem of sexual abuse of children. She reports her study of 500 mothers in the general population and 100 mothers with abused children (physical and sexual) and has shown that even in normal populations intrafamilial sexual abuse in childhood occurred in $3 \%$ of the mothers. In mothers of abused children, it rises to $24 \%$. So it is clear that, unless New Mexico is remarkably different from the United Kingdom, we are still not recognising the majority of the cases. Does it matter? Goodwin deals with this question impressively. False incest accusations represent less than $5 \%$ of their cases. In most, the father-daughter incest has started early and continued over many years. Often more than one child in the family is involved. The chimd is seriously developmentally impaired and in adolescence, suicere attempts, absconding and hysterical epilepsy are common. The genetic consequences to incestuous offspring are spelled out. And $\vec{F}$ course, the cycle repeats itself in the next generation. What can we do about it? In Santa Clara County, California, incest perpetratigrs are 'sentenced to treatment' and this book outlines the varicies treatment programmes including family therapy, individual a group psychotherapy, for parents and child, counselling by phtcians who have access to psychiatrists' support, etc. She uses famy stories, reproduced here, as a way of providing a language for youne children to use. Always, the aim is protection for the child, but imaginative ways of avoiding family destruction are being deveoped.

Reading this book has convinced me that our neglect of this problem has condemned many children to unnecessary suffering

It should be essential reading for paediatricians, gynaecologigts and psychiatrists.

Edgware Gener

DORA BLACK Middlesex.

\section{Treatment of Burns}

By J. S. CASON. Pp. 339, illustrated. Chapman \& Hall, Lond $\bar{\omega}$ 1981. £15.00.

The standard British text on burns and their treatment was for many years Muir and Barclay's book, but as the last edition of this published 10 years ago, there has recently been a need for a now book and Cason has fulfilled this need. The techniques described ate mainly those used at the Burns Unit of the Birmingham Accidont Hospital where Mr Cason is Surgeon-in-Charge, but he has been careful to describe other methods as well, including theôvery different management of shock found in some of the American centres.

The book is full of useful information, yet the style is a little and the organization somewhat odd. For instance, 'First aid' and management of a small burn' comes in the last chapter of the bo $\mathbf{k}$ whereas I would have preferred it to be placed nearer the beginni A casualty officer or registrar faced with the management of a bion would have difficulty in picking out the important points quick yet they are all there.

An introductory chapter is followed in the second chapter by the main substance of the book on 'Burns shock and its managemem'. At the end of this chapter on p. 54 is a useful list of actions to he taken in treating burns shock. As $50 \%$ of deaths are due septicaemia, it is entirely appropriate that there is a full chapter.8n infection, and this leads to a description of the general management and the treatment of the burn surface, with techniques of skn grafting. It is a pity that skin grafting is followed and not preceeded by an account of burn depth.

The problems of burn scarring are well covered, but I found so me of the techniques with the tube predicles a little dated. There ge several chapters on burns at specific sites. The account of psychological and psychiatric problems is very helpful and appliesto other accident situations. Although much of what is said is commen sense, it helps to have it stated in print, so that all the staff (includimg the nurses) have an understanding of why a patient or relatke should be unco-operative or belligerent. There is a good chapter non-accidental injury, with instructions of what to do if you uxe suspicious of a case.

At the end of the book are 17 tables or lists some of which, but non all, are useful as references. Most of the pictures, charts a diagrams are clear and useful and each chapter has a list of the maje references.

In summary, this is a useful book to have available for reference any department dealing with burns and to be read by staff likelyporo manage these cases.

B. D. G. Morgan, University College Hospital London WCI. 